\title{
The Syphilis Epidemic and its Relation to AIDS
}

\section{Citation}

Allan M. Brandt. 1988. The syphilis epidemic and its relation to AIDS. Science 239(4838):

375-380.

\section{Published Version}

http://www.jstor.org/stable/1700232

\section{Permanent link}

http://nrs.harvard.edu/urn-3:HUL.InstRepos:3372906

\section{Terms of Use}

This article was downloaded from Harvard University's DASH repository, and is made available under the terms and conditions applicable to Other Posted Material, as set forth at http:// nrs.harvard.edu/urn-3:HUL.InstRepos:dash.current.terms-of-use\#LAA

\section{Share Your Story}

The Harvard community has made this article openly available.

Please share how this access benefits you. Submit a story.

Accessibility 
the Peking Daily, and other news media.

31. D. N. Matthews, A. Bailey, R. A. Vaile, G. J. Russell, K. N. R. Taylor, Nature (London) 328, 786 (1987); R. N. Bhargava, S. P. Herko, W. N. Osborne, Phys. Rev. Lett. 59, 1468 (1987)

32. B. D. Josephson, Phys. Lett. 1, 251 (1962)

33. R. Koch et al., Proceedings of Symposium S 1987 Spring Meeting of the Materials Research Society, D. U. Gubser and M. Schluter, Eds., Anaheim, p. 81.

34. Lincoln Labs.

35. T. R. Dinger, T. K. Worthington, W. J. Gallagher, R. L. Sandstrom, Phys. Rev. Lett. 58, 2687 (1987).
36. W. J. Gallagher et al., in preparation.

37. G. W. Crabtree et al., in preparation.

38. R. J. Cava et al., Phys. Rev. Lett. 56, 1676 (1987)

39. A. Kapitulnik et al., in (4).

40. B. Oh et al., in preparation. Critical field slopes were determined from temperatures at which the resistance had fallen to $90 \%$ of the normal state value.

41. S. W. Tozer et al., Phys. Rev. Lett. 59, 1768 (1987).

42. This work was partially supported by the Air Force Office of Scientific Research and Materials Research Laboratory (MRL) program of the the National Science Foundation.

\title{
The Syphilis Epidemic and Its Relation to AIDS
}

\author{
ALLAN M. BrandT
}

This article presents an overview of the history of medical and public health responses to syphilis in the 20thcentury United States and briefly evaluates the relevance and significance of these approaches for the AIDS epidemic. The parallels are numerous: they relate to science, public health, civil liberties, and social attitudes concerning sexually transmitted infection. The strengths and limits of past approaches to controlling sexually transmitted diseases are explored as a possible guide for AIDS policy.

$\mathrm{I}$ N 1909, Nobel laureate immunologist Paul Ehrlich announced the discovery of Salvarsan, a cure for the dreaded disease syphilis. Ehrlich's discovery marked a fundamental breakthrough in the history of modern medical science; for the first time, a specific chemical compound had been demonstrated to kill a specific microorganism. Ehrlich called the substance-the 606th arsenical he had synthesized-a "magic bullet," a drug that would seek out and destroy its mark. He posited that the world of 20thcentury bioscience would be the elucidation of magic bullets to cure all diseases $(I)$.

In the midst of the AIDS epidemic, the history of modern efforts to understand and control syphilis provides an important analog. The two diseases have obvious differences, but both are sexually transmitted, have severe pathological consequences, and are greatly feared, and the patients are highly stigmatized. This suggests there may be lessons in the historical approaches to syphilis that may help us to understand the current health crisis. This article reviews the basic scientific, medical, and public health approaches to syphilis in the 20th century as well as the role of social and cultural values in shaping perspectives on the disease. In addition, it seeks to point to significant comparisons between medical and public health approaches to syphilis and the current AIDS crisis.

\section{Magic Bullets and the Biomedical Model}

Ehrlich's discovery of Salvarsan was the culmination of a generation of research that led to a profound shift in biomedicine. Indeed, the target of Ehrlich's bullet was a microorganism that had only been identified in May 1905 by two German researchers, Fritz Schaudinn, a protozoologist, and Erich Hoffmann, a syphilologist. Found in syphilitic chancres and other infected tissue, the spiralshaped organism proved difficult to stain, thus earning the name Spirochaeta pallida. Later recognized to be a treponemal organism, it was renamed Treponema pallidum (2).

The discovery of the treponeme was rapidly followed by the development of a diagnostic test for its presence. August Wassermann and his colleagues Neisser and Bruck applied the complementfixation reaction discovered by J. Bordet and O. Gengou to the spirochete (3). The test involved the application of human blood to sheep blood corpuscles. Syphilis could now be detected in the asymptomatic; moreover, the effect of treatment could now be evaluated.

These three major discoveries appeared to fulfill the promise of the biomedical revolution of the late 19th century. They rested on a generation of research on the germ theory of disease, the idea that specific diseases were caused by specific infectious organisms. In the last two decades of the 19th century, researchers following the work of Pasteur and Koch identified a number of organisms now associated with specific diseases including tuberculosis, diphtheria, typhoid, and cholera (4).

Progress was also made in determining the pathology of infectious disease. This was particularly true in the instance of syphilis. From the 16th century until well into the 19th, most doctors assumed gonorrhea and syphilis were manifestations of the same disease. In 1837, French venereologist Phillipe Ricord established the specificity of the two infections through a series of experimental inoculations from syphilitic chancres. Ricord was also among the first physicians to differentiate primary, secondary, and late syphilis, the three stages of infection (5). By the end of the 19th century, the systemic dangers of syphilis had been clarified. Because syphilitic infections appear to resolve after the initial inflammatory reaction, chronic ailments resulting from the disease had long been thought to be distinct clinical entities. Rudolf Virchow established that the infection could be transferred through the blood to the internal organs and cause significant pathology, and by 1876 cardiovascular syphilis had been clearly documented in the medical literature. If the

The author is an associate professor in the Department of Social Medicine and Health Policy, Harvard Medical School, Boston, MA 02115. 
infection spread to the spinal cord, it could lead to muscular incoordination and partial paralysis (tabes, locomotor ataxia, paresis) or complete paralysis (6). Ultimately affecting the brain, syphilis also led to blindness and, in some cases, insanity. By the early 20th century, mental institutions reported that as many as one-third of all patients could trace their symptoms to syphilitic infection (7).

The wide variety of syphilitic pathologies led William Osler, the most distinguished clinician in the United States, to tell his students at the Johns Hopkins Medical School, "Know syphilis in all its manifestations and relations, and all other things clinical will be added unto you" $(8$, p. 134). On another occasion he called syphilis the "great imitator," because its symptoms were similar to diseases with other etiologies $(9)$.

Until the introduction of Salvarsan, syphilis was treated in a variety of ways, but principally with mercury. Debates continue about the antitreponemal properties of heavy metals, but it is clear that mercury did not cure syphilis, and it was quite toxic, causing loss of teeth, tongue fissures, and hemorrhaging of the bowel. The state of therapeutics in the late 19th century explains in part the high estimates of the incidence of infection; most studies suggested that $10 \%$ of the population was affected. Although the precise levels of infection cannot be known, even conservative estimates indicated that, in the absence of effective treatments, syphilis was a health problem of enormous dimensions (10).

Salvarsan remained the treatment of choice for syphilis until the discovery of the effectiveness of penicillin in 1943. Ehrlich's magic bullet had its shortcomings; it was toxic, difficult to administer, and required an extensive regimen of treatment, sometimes for as long as 2 years. Only $25 \%$ of all treated patients apparently received the full complement of injections (11). But at the time of its discovery, it was heralded as the dawn of the modern age of clinical medicine. Physicians throughout the world sought supplies of the drug and reported miraculous recoveries from the disease.

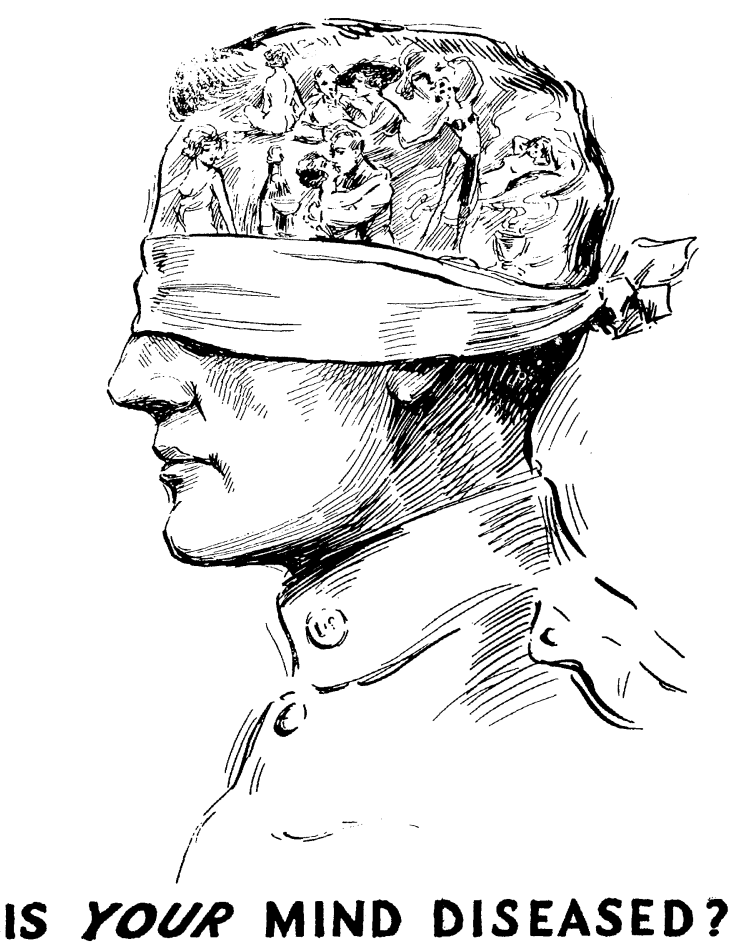

SOCIAL HYGIENE DIVISION ARMY EDUCATIOMAL COMMISSION

Fig. 1. A poster from the U.S. Army's campaign against venereal disease.

\section{Syphilis and Progressive Medicine}

The developments in biomedicine in the late 19th and early 20th centuries came at a time of rising concern in Western societies about sexual mores, the family, and the nature of urban life. Indeed, even before the discovery of Salvarsan, the American medical profession had organized to fight sexually transmitted diseases and expressed alarm about their social impact. The problem of syphilis was seen as one dimension of a larger breakdown in values that emphasized the sanctity of the home, the domestic role of women, and the principle of strictly marital sexuality (12).

Physicians focused attention on the impact of sexually transmitted infections on the family or what they called "innocent infections." The train of family tragedy was a frequent cultural theme in these years. In 1913 a hit Broadway play by French playwright Eugene Brieux, Damaged Goods, told the story of a young man about to be married who contracts syphilis. Though warned by his physician not to marry, he disregards this advice only to spread the infection to his wife and, later, to their child. The story revealed deep cultural values about science, social responsibility, and the limits of medicine (13). The knowledge that profligate men "visited" their sins upon their wives and children led to a dramatic change in professional attitudes. Previously called a "carnal scourge," syphilis was redefined as "family poison." In 1906, the American Medical Association held a symposium on the Duty of the Profession to Womanhood. One physician at the conference explained (14):

These vipers of venery which are called clap and pox, lurking as they often do, under the floral tributes of the honeymoon, may so inhibit conception or blight its products that motherhood becomes either an utter impossibility or a veritable curse. The ban placed by venereal disease on fetal life outrivals the criminal interference with the products of conception as a cause of race suicide.

Although physicians frequently centered attention on the impact of the diseases on fertility, they also examined the wider social repercussions of infection. Immigration to the United States was at its height during the last years of the 19th century and the first years of the 20th; more than 650,000 immigrants arrived each year between 1885 and 1910. Many doctors and social critics suggested that these individuals were bringing syphilis and other venereal diseases into the country. Howard Kelly, a gynecologist at Johns Hopkins, warned $(15,16)$ :

The tide [of venereal disease] has been raising [sic] owing to the inpouring of a large foreign population with lower ideals.... Think of these countless currents flowing daily from the houses of the poorest to those of the richest, and forming a sort of civic circulatory system expressive of the body politic, a circulation which tends to equalize the distribution of morality and disease.

Medical examinations at the ports where immigrants entered the United States failed to reveal a high incidence of disease; nevertheless, nativists called for the restriction of immigration. How were these immigrants spreading sexually transmitted disease to native, middle-class, Anglo-Saxon Americans? First, it was suggested that immigrants constituted the great bulk of prostitutes who inhabited American cities. Second, physicians now asserted that syphilis could be spread in any number of casual ways. Doctors catalogued the various modes of transmission: pens, pencils, toilet seats, doorknobs, and drinking cups (17). We now know, of course, that syphilis cannot be transmitted in these ways. This poses an important historical question: Why did physicians believe it could be?

Theories of casual transmission of syphilis reflected deep cultural fears about disease and sexuality in the early 20th century (Fig. 1). Syphilis was viewed as a threat to the entire late Victorian social and sexual system, which placed great value on discipline, restraint, and homogeneity. The sexual code of this era held that only sex in 
marriage should receive social sanction. But the concerns about syphilis also reflected a pervasive fear of the urban masses, the growth of the cities, and the changing nature of familial relationships (12). Finally, the distinction between syphilis and syphilis of the innocent had the effect of dividing victims; some deserved attention, sympathy, and medical support, others did not. This, of course, depended on how the infection was obtained. Implicit in the notion of "innocent" infection was the suggestion of culpability for the epidemic.

\section{Syphilis and World War I}

By the time of World War I, concern about syphilis had reached unprecedented heights. The military draft and consequent physical examinations had revealed high rates of infection-13\% of those drafted were found to be infected with either syphilis or gonorrhea (18). The war touched off the most vigorous antivenereal disease campaign in American history.

Although the military devised a program of vigorous exercise and explicit sexual education for the troops, the campaign centered on the problem of prostitution. Virtually every American city had an active prostitution trade in the early 20th century. It was now feared that soldiers in training would visit prostitutes, become infected, and be lost to the war effort. The military now viewed these redlight districts as a potentially catastrophic health risk for the troops. Posters, films, and other educational materials repeatedly warned the soldiers, "A German bullet is cleaner than a whore" (19).

Closing down red-light districts became part of the "hygienic gospel," comparable to the antituberculosis and anti-yellow fever campaigns waged in these years. One federal official stated that "To drain a red-light district and destroy thereby a breeding place of syphilis and gonorrhea is as logical as it is to drain a swamp and thereby a breeding place of malaria and yellow fever" (20). As a result, local governments closed down their districts of prostitution. In July 1918, the U.S. Congress took action to support local and state initiatives by enacting the Chamberlain-Kahn Act, establishing a "civilian quarantine and isolation fund," as part of a comprehensive venereal disease program. More than 20,000 women were quarantined during the war with the assistance provided by federal funds, thousands more were incarcerated as a result of local programs $(12,21)$. Barbed wire and guards secured many of the institutions. A total of 110 districts such as "Storyville," New
Orleans, and the "Barbary Coast," San Francisco, were closed down during the course of the war. One federal official noted (22):

Conditions required the immediate isolation of as many venereally infected persons acting as spreaders of disease as could be quickly apprehended and quarantined. It was not a measure instituted for the punishment of prostitutes on account of infraction of the civil or moral law, but was strictly a public health measure to prevent the spread of dangerous, communicable diseases.

Fear of venereal disease during the war led to substantial inroads on traditional civil liberties in the name of public health. Although many of these interventions were challenged in the courts, most were upheld; the police powers of the state were deemed sufficient to override any constitutional concerns. Legal restraints, of course, fell most heavily on those considered "responsible" for the disease.

Closing down red-light districts in the United States had little bearing on the situation in France, where American troops arrived "to make the World safe for democracy." The Army officially forbade the soldiers from using the French regulated houses of prostitution. This angered French officials who believed that American demand for street prostitutes-known as clandestines-would defeat their regulatory system of medical inspections of brothels.

Although it was widely recognized that latex condoms, available since the 19th century, prevented the transmission of syphilis, the military declined to provide them to the troops. It was assumed that providing condoms would merely encourage sexual relationships. Instead, the military established a series of prophylactic stations where a soldier could take a disinfectant treatment after a sexual exposure. The treatment, which involved an injection into the urethra, was painful and intended to serve as an inhibition to sex. Some reformers protested, nevertheless, that the provision of such treatments promoted promiscuity among the troops when reports of long lines at the stations appeared in the press. Failure to undergo the treatment and the eventual contraction of an infection was considered a court-martial offense. The Army ruled that sexually transmitted diseases were injuries incurred "not in the line of duty," and infected soldiers lost their pay (23) (Fig. 2).

Despite these major efforts in social engineering and public health, rates of disease remained high during the war. The incarceration of prostitutes apparently did not serve as an effective public health measure. The war effort did reveal, however, the lengths to which the military and public health officials would go in their attempts to control venereal disease. The war tested the basic assumptions of the social hygiene movement: rigorous education
Fig. 2. A dishonorable discharge was an outcome of contracting a venereal disease. In contrast, a reminder of American family values was intended to deter promiscuity.
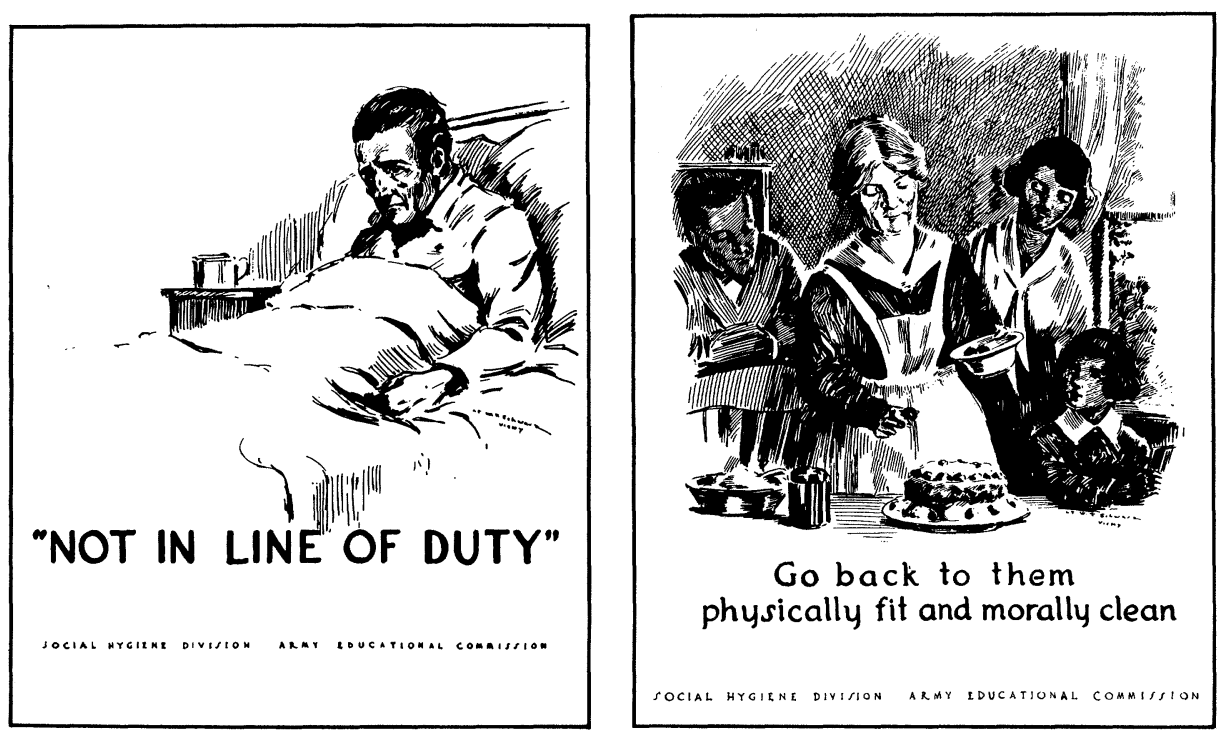
promoting sexual abstinence coupled with vigorous repression of prostitution would conquer the problem. The war revealed the limits of this approach.

\section{Thomas Parran, Surgeon General}

Although efforts against syphilis lagged in the 1920s, they were reinvigorated in the 1930s when President Franklin Roosevelt appointed Thomas Parran as Surgeon General. Parran, a career public health officer, had witnessed the precipitous decline of communicable diseases such as diphtheria and typhoid, while in the same years rates of syphilis had climbed. This seemed particularly ironic in the face of the development of laboratory diagnosis and specific treatments. "Syphilis does a hundred times as much damage as poliomyelitis," Parran explained in 1936 (24), "yet we can cure it. We still do not know how to cure poliomyelitis, only how to mitigate it." He touched off a national campaign against syphilis when he wrote Shadow on the Land, a book devoted to exposing the national problem of syphilis (25).

Parran developed a five-point plan to conquer syphilis, basing his program on traditional public health precepts. First, was the need to find cases. For this purpose, he called for the establishment of diagnostic centers where individuals could obtain free, confidential tests. The rationale behind finding these cases was to bring infected individuals under immediate treatment. Thus prompt therapy constituted Parran's second recommendation; delay after infection made treatment more difficult and increased the possibility that others would be infected. Third, Parran advocated tracing of all sexual contacts of infected individuals so that they too could be tested and treated if necessary. To prevent infection among marital partners and their children, he called for mandatory premarital and prenatal blood testing. Finally, the Surgeon General recommended a massive program of public education emphasizing prevention and the need for recognition of symptoms and treatment if infection occurred.

Parran explicitly sought to avoid the traditional moralistic perspectives on syphilis that held that the disease was the result of moral turpitude. He sought to divorce his program from the traditional concerns of the social hygienists. Nevertheless, he found that he was repeatedly blocked by social conventions that held that public discussion of syphillis and other venereal diseases was inappropriate. Despite the brief interruption during World War I, syphilis remained cloaked in what was known as "the conspiracy of silence"it was not to be discussed in respectable society. As Prince Morrow, the leader of the social hygiene movement, had noted in 1906: "Social sentiment holds that it is a greater violation of the properties of life publicly to mention venereal disease than privately to contract it" (26). Paul de Kruif, a science writer, had repeatedly attempted to place an article on syphilis in the Ladies Home Journal without success. When Parran attempted to discuss the problem of venereal disease in a radio broadcast on CBS in 1934, he was censored from using the words syphilis and gonorrhea $(12,27)$.

Parran sought to break through the "conspiracy of silence" to "stamp out syphilis." The culmination of Parran's campaign was the passage of the National Venereal Disease Control Act in 1938. The Act provided for federal grants to the state boards of health to develop programs against venereal disease. Congress allocated \$15 million over a 3-year period to support clinics and educational activities (28). The number of state-supported clinics rose from 1750 in July 1938 to almost 3000 by 1940 . Diagnostic laboratories were expanded, as were epidemiological services and treatment facilities for those who could not afford them. The number of serological tests administered by state laboratories increased by

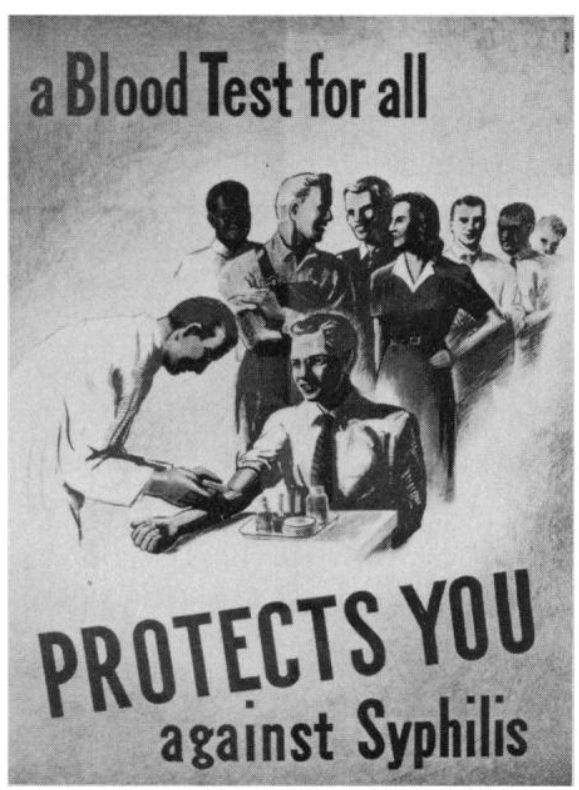

Fig. 3. A public health poster from the 1930s campaign advocating syphilis serologies.

300\% between 1936 and 1940; funds from the Act helped to make the necessary diagnostic facilities available. "Since the detection of syphilis is to a large extent dependent upon mass blood-testing," noted Raymond Vonderlehr of the U.S. Public Health Service, "this increase in laboratory tests for syphilis is perhaps the best index of the effort which has been made to discover and bring to treatment infected individuals" $(29$, p. 132$)$. This meant that more cases now came under treatment during the early stages of the disease when therapy proved most effective. The "shadow on the land" had begun to lift.

The public health campaign increasingly focused on the use of serological tests (Fig. 3). In 1935, Connecticut passed the first legislation requiring a blood test and physical examination for all prospective brides and grooms. By the end of 1938, 26 states had enacted provisions prohibiting the marriage of infected individuals (30). Most of these states now required individuals seeking a marriage license to take a blood test for syphilis. An individual would have to be found to be noninfectious in order to proceed with the marriage.

The tests rested on a series of assumptions about sexuality that were not always reflected empirically. It was assumed that everyone would eventually pass through the sieve of marriage; all infections would then be discovered and treated. The legislation never explicitly recognized the nature of sexual mores and the issue of premarital and extramarital sexuality. As syphilologists John Stokes and Norman Ingraham noted in 1939, "The fact that sexual intercourse has preceded application for the certificate [of marriage] is such a commonplace that it is a question whether the mere withholding of its issuance ... has more than a small fraction of the preventive significance attached to it" (31).

Public health officials also encouraged voluntary testing and treatment. In Chicago, for example, with the assistance of publicity provided by the Chicago Tribune, the local, state, and federal health bureaucracies developed a comprehensive plan to rid the city of syphilis. Questionnaires were mailed to more than a million Chicago families to ascertain their interest in such a campaign. More than 261,000 persons indicated their desire to receive a free blood test. At the height of the program, 10,000 to 12,000 individuals daily were tested in what Parran called a "Wassermann dragnet." Between 1937 and 1940 over $31 \%$ of the city's entire adult population received Wassermann tests. Some 56,000 individuals infected with syphilis were identified and treated-all at public expense (32). 
Fig. 4. Venereal disease, represented as an evil woman, was viewed as a military enemy in World War II.

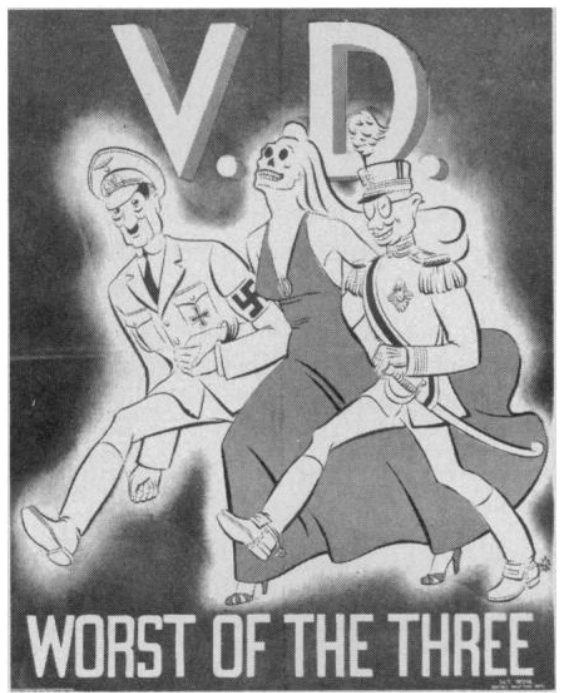

Parran's program, which emphasized case-finding and treatment, was never systematically evaluated. His campaign did, however, lead to a better public understanding of the significance of infection and ways to avoid it. The broader provision of diagnostic and treatment facilities led to a decline in rates of infection. Compulsory premarital screening, however, adopted by virtually every state between 1935 and 1945, never proved to be an effective means of finding new cases. Physicians pointed to the problem of false positive tests that could occur because of technical problems with the test or as a result of biological phenomena. As the concepts of sensitivity (the test's performance among those with the disease) and specificity (the test's performance among those free of infection) were clarified, the oversensitivity of tests like the Wassermann was revealed. As many as $25 \%$ of individuals who tested positive were actually free of infection; nevertheless, these individuals often underwent toxic treatment on the assumption that the tests were correct. With syphilis, a positive blood test did not always mean that an individual was capable of transmitting the disease. Although the tests were refined, inaccuracies did persist. Moreover, the tests tended to be directed at a group at relatively lower risk of infection; this further compromised their accuracy. Finally, there is some evidence that infected individuals merely avoided the test altogether (33).

Many of the difficulties associated with high numbers of false positives were alleviated as new more specific tests were developed in the 1940s and 1950s, but the central problem remained; premarital tests failed to identify a significant percentage of the infected population. For example, in 1978 premarital screening accounted for only $1.27 \%$ of all national tests found to be positive for syphilis. The costs of these programs were estimated at $\$ 80$ million annually (34). It seems likely that premarital screening rarely served the function of preventing infections within marriage that its advocates assumed it would. These data led a number of states to repeal mandatory serologies in the early 1980 s.

\section{Syphilis in the Age of Antibiotics}

During World War II antisyphilis efforts again intensified. A major campaign against prostitution was initiated, as were efforts at public education. But unlike the policy instituted in World War I, the military decided that the troops must be equipped with condoms to prevent infection. The military program, which combined a massive education program (Fig. 4), prophylaxis, and rapid treatment without punitive measures proved to be highly successful as rates of disease were controlled. With the additional therapeutic breakthrough of penicillin, the military had the armamentarium to control the disease (35).

In early 1943, John S. Mahoney of the U.S. Public Health Service, using a strain of penicillin provided by Howard Florey and Ernst Chain at Oxford, found that the drug was effective in treating syphilitic rabbits. Realizing the potential implications of his discovery, Mahoney moved directly to repeat the experiment with human subjects. By September he had announced his findings and the massive production of penicillin was under way (4).

Just as Ehrlich's discovery had constituted a revolution in modern therapeutic approaches to infectious disease, so now penicillin beckoned the era of antibiotics. The incidence of syphilis fell from a high of 72 cases per 100,000 in 1943 to about 4 per 100,000 in 1956 (35). In the last years of the 1950s, as rates of infection reached all-time lows, it appeared that syphilis would join the ranks of other infectious diseases that had come under the control of modern medicine.

Despite the widespread availability of antibiotics, rates of syphilis began to climb again in the early 1960s. Although many public health officials and physicians attributed this increase to what they called the three "p's," permissiveness, promiscuity, and "the pill," the rise also correlates with a substantial fall in funding for public venereal disease programs. From a high of $\$ 18$ million allocated in 1947 , the federal venereal disease budget fell to $\$ 3$ million in 1955 . By the late 1950s much of the machinery, especially procedures for public education, case-finding, tracing, and diagnostics, had been cut back (36).

The bitter irony of syphilis is that the "magic bullet" did not eliminate the disease. The Centers for Disease Control recently reported an increase in cases of primary and secondary syphilis. The estimated annual rate per 100,000 population rose from 10.9 to 13.3 cases, the largest increase in over 10 years $(37)$.

\section{AIDS in Historical Perspective}

AIDS, obviously, is a disease considerably different from syphilis. Caused by a human retrovirus, human immunodeficiency virus (HIV), it attacks the immune system, leaving affected individuals vulnerable to a host of other infectious agents. In addition to being transmitted sexually, HIV can be transmitted through blood transfusion as well, thus making intravenous drug users who share needles a principal risk group for infection. Unlike the statistics for syphilis, in AIDS, principal morbidity and mortality occur among young people; the most serious consequences of syphilis usually come in the late stage of the disease, among older individuals. Finally and most significantly, at this moment there are no curative treatments for AIDS and no means of rendering infected individuals noninfectious. Despite these important differences, however, the history of syphilis presents a series of striking parallels to the many problems raised by AIDS.

AIDS, like syphilis in the past, engenders powerful social conflicts about the meaning, nature, and risks of sexuality; the nature and role of the state in protecting and promoting public health; the significance of individual rights in regard to communal good; and the nature of the doctor-patient relationship and social responsibility. The analogs that AIDS poses to this brief history of syphilis are striking: the pervasive fear of contagion, concerns about casual transmission, the stigmatization of victims, and the conflicts between public health and civil liberties. The response to AIDS will be a function of our own time, our own culture, and our own science. The importance of the history of syphilis is that it reminds us of that range of forces that influence disease, health, and social policy. 
Throughout the 20th century the debate about sexually transmitted diseases has swung between two essential approaches to the problem. The first, clearly articulated by the social hygiene movement, contended that the best way to prevent infection was by adherence to a sexual ethic that made it impossible to acquire an infection. Essentially this meant restricting sexual relationships to marriage. The principal means of achieving this goal was through education to encourage abstinence and the repression of prostitution, assumed to be the central locus of infection. The alternative view, instrumental in orientation, sought to sever the problem of sexually transmitted diseases from any particular sexual ethic. According to this position, represented in Thomas Parran's approach during the 1930s, individuals should be provided with means of preventing infection and, if infected, appropriate treatment.

These two long-standing approaches have been widely voiced in the first 5 years of the AIDS epidemic. Adherents of the moral approach argue that the instrumental approach actually encourages infection by unwittingly promoting sexual behavior-according to this argument good morals and good health go hand in hand. Advocates of the instrumental orientation counter that the moralists promote infection by restricting access to explicit education and preventive techniques. Both approaches reflect implicit social values about sexuality, medicine, and disease.

It is important to realize that merely invoking the public health approaches that have characterized antisyphilis programs is unlikely to stem the tide of the AIDS epidemic. Screening of low-prevalence populations, such as premarital couples, is unlikely to have any significant impact on the course of the epidemic. Not only will such programs find relatively few new cases, they will also find relatively large percentages of false positives (38). Moreover, the inability to treat and render noninfectious those individuals found to be infected severely limits the potential benefits of such mandatory measures.

Other programs, however, attempted in the past, may offer strategies for the future. Intensive education programs during World War II informed soldiers of risks and the widespread provision of condoms protected them from infection. Voluntary confidential testing during the 1930s led to a decline in rates of infection in certain urban areas like Chicago. Such programs, considered radical at those times, may provide some insights for contemporary approaches to combat AIDS.

The search for magic bullets against AIDS will continue in the years ahead. But it is worth remembering that even a magic bullet will not end the AIDS epidemic. Both syphilis and AIDS reveal certain limitations of the biomedical model of disease. No doubt, effective treatments for specific diseases are a critical component in their control, but as the history of syphilis indicates, they are not a panacea. Infectious diseases constitute complex bioecological problems in which host, parasite, and a range of social and environmental forces interact (39). No single medical or social intervention can thus adequately address the problem. Just as penicillin did not "solve" the problem of syphilis, no single treatment or even vaccine is likely to free us from AIDS, at least in the immediate future. Just as social mores and practices change, so too the biological system is in flux. New infections such as AIDS may appear, or infectious diseases once controlled may become intransigent as the organism itself changes.

For this reason, it seems that a more complex model of disease is required to effectively direct policy-a model sensitive to the varied biological, psychological, and social factors shaping the nature of disease (40). Both the syphilis and the AIDS epidemics strongly suggest the need to better understand the relationship of human behavior to health. Behavior is subject to a range of influences, biological and cultural, economic and political. As the history of syphilis demonstrates, the modification of behavior to reduce risk of disease has rarely responded simply to fear or moral exhortation. In this light, considerable social science and behavioral research is required to identify effective approaches to education and behavior modification.

In the meantime, the devices of bioscience, clinical medicine, and public health will be powerfully tested by the AIDS epidemic. As the history of syphilis makes clear, the response to AIDS will clarify the very nature of our science, culture, and society (41). In this sense, AIDS, like all epidemic disease, constitutes a natural experiment in the ability of social institutions to respond effectively and humanely to a biological crisis.

\section{REFERENCES AND NOTES}

1. M. Marquardt, Paul Ehrlich (Schuman, New York, 1951).

2. W. A. Pusey, Syphilis as a Modern Problem (American Medical Association, Chicago, 1915), pp. 31-35.

3. A. Wassermann, A. Neisser, C. Bruck, Dtsch. Med. Wochenschr. 32,745 (1906).

4. H. Dowling, Fighting Infection: Conquests of the 20th Century (Harvard Univ. Press, Cambridge, MA, 1977)

5. J. T. Crissey and L. C. Parish, The Dermatology and Syphilology of the Nineteenth Century (Praeger, New York, 1981).

6. W. A. Pusey, The History and Epidemiology of Syphilis (Thomas, Springfield, IL, 1933), pp. 53-61

7. H. F. Swift and A. W. M. Ellis, N.Y. Med.J. 96, 53 (1912); H. Noguchi and J. W. Moore, J. Exp. Med. 17, 232 (1913).

8. W. Osler, Aequanimitas and Other Addresses (Blakiston, Philadelphia, ed. 3, 1932). 9. Lancet 1917-I, 789 (1917).

10. P. Morrow, N.Y. Med.J. 74, 1146 (1901).

11. P. S. Ward, J. Hist. Med. 36, 59 (1981).

12. A. M. Brandt, No Magic Bullet: A Social History of Venereal Disease in the United States Since 1880 (Oxford Univ. Press, New York, 1985; reprinted 1987), pp. 747.

13. E. Brieux, Damaged Goods (Brentano's, New York, 19] $\rightarrow$ B. G. Rosenkrantz, Milbank Mem. Fund Q. 57, 1 (1979)

14. A. H. Burr, J. Am. Med. Assoc. 47, 1887 (1906).

15. H. Kelly, Trans. Am. Soc. Social Moral Prophylax. 1, 75 (1906).

16. $\longrightarrow$ Social Dis. 1, 17 (1910).

17. L. D. Bulkey, Syphilis of the Innocent (Bailey and Fairchild, New York, 1894).

18. U.S. War Department, Annual Report 1918 (Government Printing Office, Washington, DC, 1918), p. 18; A. G. Love and C. B. Davenport, Defects Found in Drafted Men (Government Printing Office, Washington, DC, 1920), p. 34

19. Colonel Care Poster Series (n.d. 1918?) in American Social Hygiene Association Papers, folder 113:6, University of Minnesota at Minneapolis-St. Paul

20. Program of Protective Social Measures (U.S. Interdepartmental Social Hygiene Board, Washington, DC, 1920).

21. Annual Report of the U.S. Interdepartmental Social Hygiene Board (Government Printing Office, Washington, DC, 1920); M. M. Dietzler, Detention Houses and Reformatories (U.S. Interdepartmental Social Hygiene Board, Washington, DC, 1922).

22. C. C. Pierce, Am. J. Obstet. 80, 629 (1919).

23. F. W. Weed, The Medical Department of the United States Army in the World War, (Government Printing Office, Washington, DC, 1926), vol. 6, pp. 936-937.

24. T. Parran, Surv. Graphic 25, 411 (1936).

25. Shadow on the Land (Reynal and Hitchcock, New York, 1937).

26. P. Morrow, J. Am. Med. Assoc. 47, 1247 (1906).

27. N. Engl. J. Med. 211, 1031 (1934); New York Post, 20 November 1934.

28. Annual Report of the Surgeon General of the U.S. Public Health Service, 1938 (Government Printing Office, Washington, DC, 1938), p. 127.

29. Annual Report of the Surgeon General of the U.S. Public Health Service, 1940 (Government Printing Office, Washington, DC, 1940), pp. 132-135.

30. E. A. Macy, Survey 74, 262 (1938); W. F. Snow, Am. J. Syph. 23, 277 (1939).

31. J. H. Stokes and N. R. Ingraham, J. Am. Med. Assoc. 112,1136 (1939).

32. O. C. Wenger, "Annual Report Chicago Syphilis Control Program" (June 1941), National Archives, Washington, DC, record group 69; P. de Kruif, Fight for Life (Harcourt Brace, New York, 1938), pp. 284-311.

33. H. S. Cumming et al., J. Am. Med. Assoc. 103, 1705 (1934); W. McDermott, Daedalus 106, 144 (1977)

34. Y. M. Felman, Am. J. Publ. Health 71, 155 (1981).

35. W. J. Brown et al., Syphilis and Other Venereal Diseases (Harvard Univ. Press, Cambridge, MA, 1970)

36. O. W. Anderson, Syphilis and Society: Problems of Control in the United States 19121964, Res. Ser. 22 (Center for Health Administration Studies, Chicago, 1965)

37. Centers for Disease Control, Morbid. Mortal. Weekly Rep. 36, 393 (1987)

38. P. Cleary et al., J. Am. Med. Assoc. 258, 1757 (1987).

39. L. Eisenberg, "Human health ecology: The control of disease," paper presented at WHO Meeting on Human Ecology and Health, Delphi, Greece, 30 September 1986.

40. G. L. Engel, Science 196, 129 (1977)

$\rightarrow$ C. E. Rosenberg, Milbank Mem. Fund Q. 64, 34 (1986)

42. This project was supported in part by BRSG S07 RR 05381-26 awarded by the Biomedical Research Support Grant program, Division of Research Resources, National Institutes of Health. 